\title{
RESEARCH ARTICLE Drawing Sound as Landscape
}

\author{
David N Buck*
}

This essay discusses the relationship between music notation, sound, and landscape. I explore how the notation of musical sounds might lead to new methods for drawing auditory landscapes. There are three components to the research: an analysis of the score of English composer Michael Finnissy's composition Green Meadows (1977); a reference to ethnomusicology to explore how the notation of sound-as-music might allow us to draw sound-as-landscape; and a notation to investigate the composition of a landscape through sound. In conclusion, I question how auditory landscapes might be composed, and suggest ways in which both drawing and sound might be considered landscape.

Often too the road would appear to dive into some dark abyss, a cataract roaring at the bottom: while the mountain-torrents on every side rushed down the hills in notes of various cadence, as their quantities of water, the declivities of their fall, their distances, or the intermission of the blast, brought the sound fuller, or fainter to the ear; which organ became now more alert, as the imagination depended rather on it, than on the eye, for information. (Gilpin 1808: 21)

This paper addresses a silent aporia in current landscape architecture discourse: the forgotten component of sound so vividly described in 1772 by William Gilpin above (Gilpin 1808: 21). I explore how a synthesis of music notation with landscape architecture might, first, allow sound to be drawn,

\footnotetext{
* UCL, The Bartlett School of Architecture, United Kingdom info@db-land.com
}

and, secondly, landscape to be created. Conventionally, design notations ${ }^{1}$ have referred to the rigid syntactic and semantic requirements set out by Nelson Goodman in The Languages of Art (1976) to prevent ambiguity of symbols and to ensure compliance between all subsequent performances of a notation. This deference to a fixed symbolic language of notation has led landscape designers to focus on the more easily mappable constituents of landscape, space and time, while ignoring the less obvious, the transitory and the qualitative. Instead of this narrow definition, the notations described below draw on the open possibilities inherent in Italian composer Ferruccio Busoni's assertion that 'notation is itself the transcription of an abstract idea' (Busoni 1965: 73). He believed that the process of creative transcription required in the reworking of others' compositions was as much notation as the action of putting new sounds onto paper. The landscape notations described below draw directly on Busoni's work, transcribing a musical score to re-imagine landscape through notation. 


\section{Pink Elephants}

Written for Queen Elizabeth's Silver Jubilee in 1977, Green Meadows was chosen by Finnissy to explore the sounds of an English landscape. His composition builds on a deep tradition of landscape-inspired music in England, either referencing real pastoral scenes, such as in Edward Elgar's Cello Concerto (1919), or idealized landscapes, as in Hubert Parry's Jerusalem (1916). The musicologist Ian Pace describes the sound of Finnissy's solo piano piece in this way:

Tempestuous yet distant surges of activity all around the keyboard erupting into split-second violence. Low rumblings, building to a peak, then calm again. Emergent shimmerings, extremely quiet, using all registers. Sudden cut off. Violent but exhilarating traversals up and down keyboard, continually under threat of envelopment by the ascending swathes of notes. A gap in the texture, appearance of more diatonic melody in mid- dle register. Top line dissolves, bottom line suddenly returns to rumblings. Alternation of more measured and spacious violence, now with monadic diatonic melody, accompanied first by rumblings, then by top register melody (now ppp). Long, timeless, exposition of serene but infinitely distant melody. Rumblings again. 'Almost motionless' continuation of melody leading to second movement. (Brougham et al 1997: 66-67)

My analytical notation explores Finnissy's strategies for volume and duration in this evocation of an imagined English landscape. My drawings, made with charcoal on 320 gram white A1 paper, started with a single pink elephant stamped onto the surface. This was in thanks to Michael Finnissy for his riposte that while a dot between two lines on conventional manuscript paper denotes the pitch $C$, as all notation is symbolic, it could equally well have been a pink elephant (figure 1).

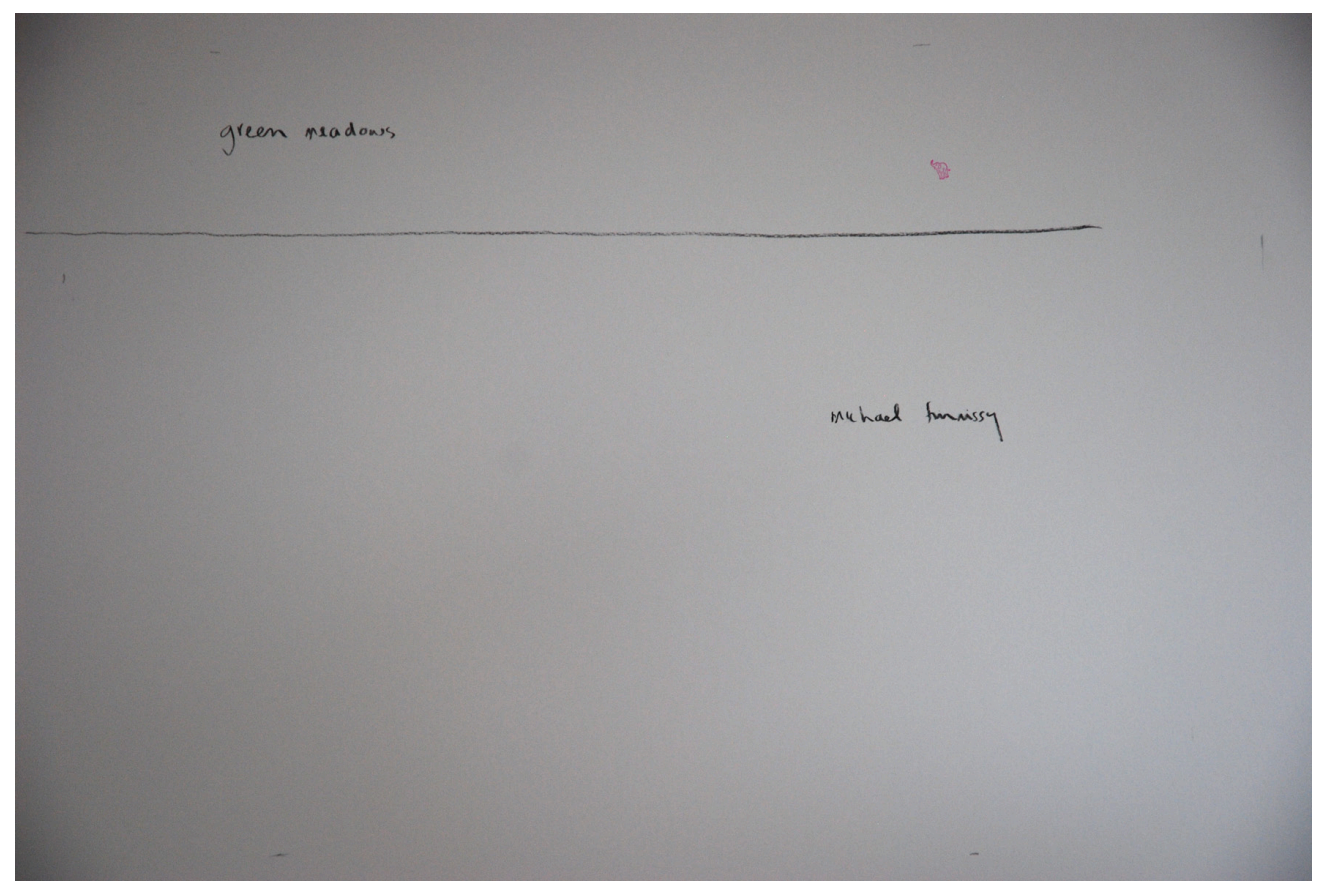

Figure 1: Initial notational marks. David Buck, charcoal on paper, 1126mmx1600mm, 2013. 


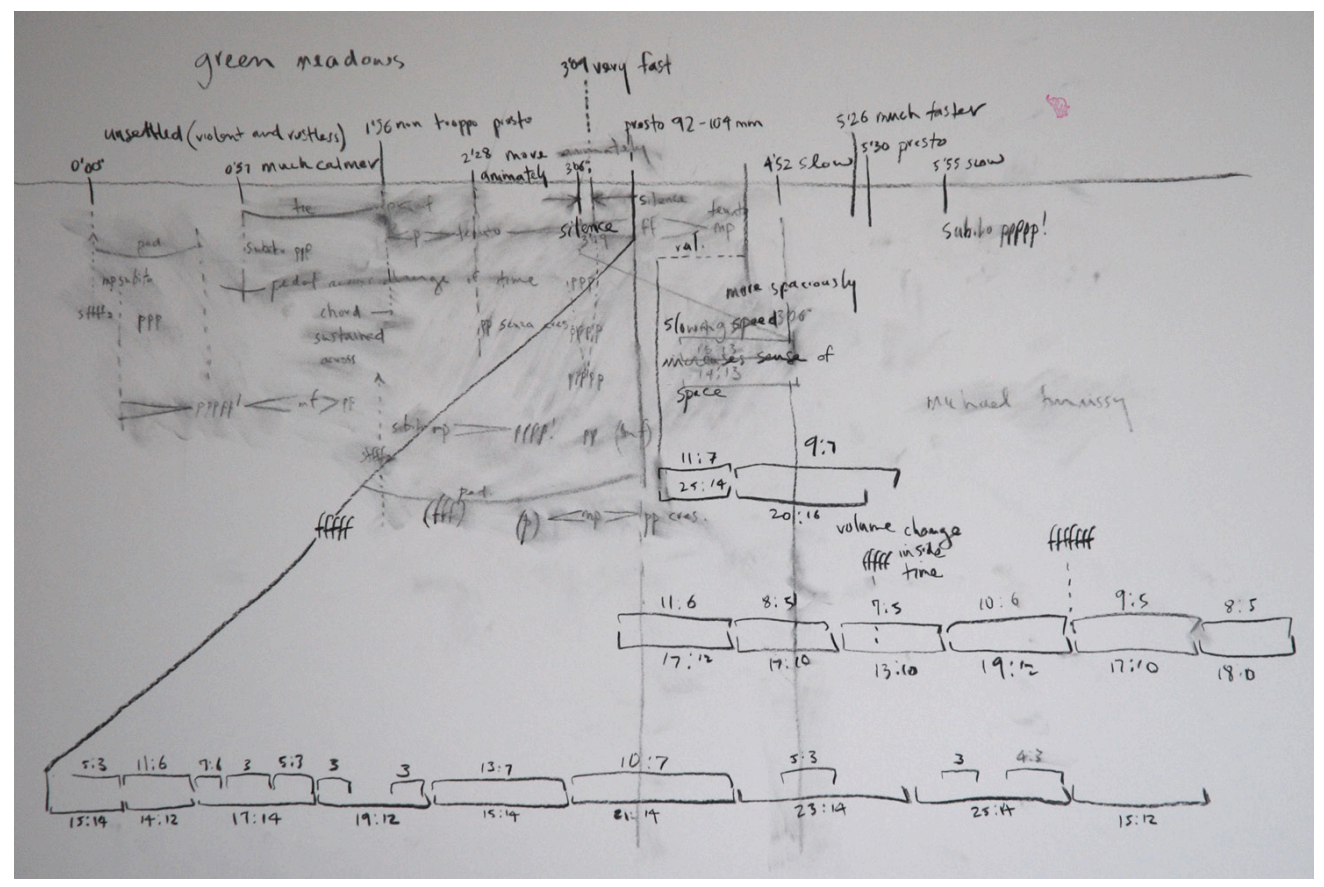

Figure 2: Temporal analysis of Green Meadows. David Buck, charcoal on paper, $1126 \mathrm{~mm}$ x1600mm, 2013.

There is a pronounced spatial quality to Green Meadows derived from a dramatic use of dynamics. Finnissy extends the conventional eight degrees separating pianissimo from fortissimo, to a range of fifteen divisions, from ppppp to fffffff. By moving sound from the barely perceptible to the territory even closer to silence, and, conversely, towards loudness, the auditory space he creates is made both more intimate, and also more expansive.

Finnissy's approach to time is personal, plastic, and innovative. This is immediately obvious in the score, which starts with the words 'unsettled (violent and restless)', replacing a conventional tempo articulated in beats per minute. He also creates tension in the music through the simultaneous sounding of sections that are slowing down (ralentando) with complex, aperiodic rhythmic patterns. Rather than the temporal tension conventionally created through subdivisions of a pulse, Finnissy's score creates slight temporal displacements between the left and right hand of the performer. These include 8:5 in the left hand against 17:10 in the right, followed by $7: 5$ against 13:10, and then 11:7 against 25:14, all small ruptures in the flow of time. Finnissy, in this use of complex temporality within a spatial expanse, has constructed the landscape of Green Meadows through sound (figure 2).

\section{Six Hundred and Fifty Five Seconds}

The second notation focuses on the landscape of Girraween National Park in Australia. I examine whether the notation of sound-as-music might also allow us to also draw sound-as-landscape. In order to include the un-pitched tones and aperiodic time found in landscape, the notation references related strategies from ethnomusicology, the study of musical cultures outside those of Western classical music. Particularly, the study focuses on the writings of the pioneering American Mantle Hood who, through his study of Javanese gamelan music, developed new methods 


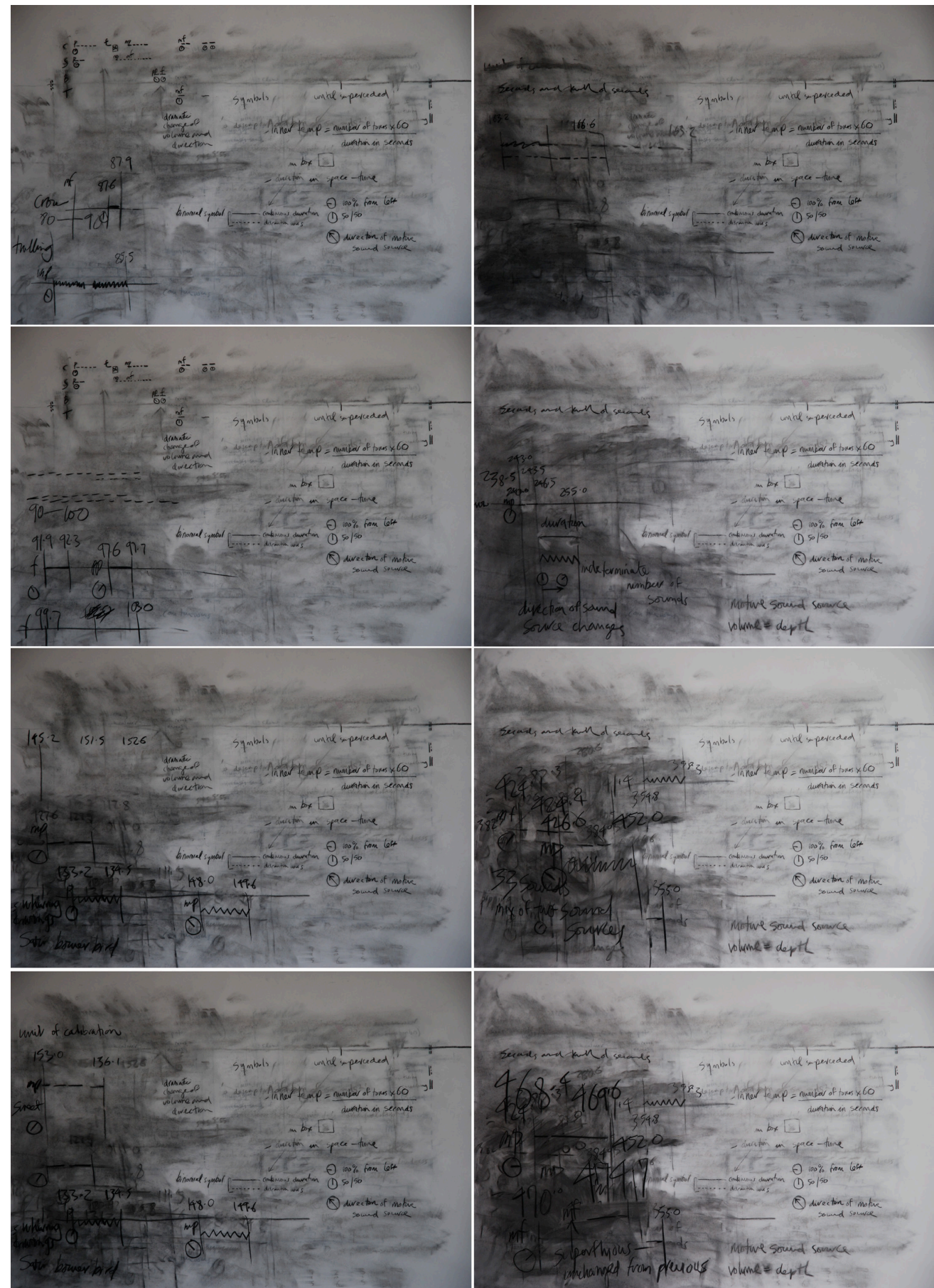

Figure 3: Extracts from the film Six Hundred and Fifty Five Seconds, a descriptive notation of landscape sounds. David Buck, charcoal on paper, 1126mmx1600mm, 2013. To be read vertically from upper left. To view the video, see DOI: http://dx.doi.org/10.5334/opt.cb.1. David Buck, video duration 2'43", 2013. 
to allow Western musicians to perform music from other cultures. In 1971, he proposed the (Alfred James) Hipkins Solution to the challenges of adapting conventional Western music notation through adding diacritical amendments "to supplement the symbolic language ... with graphic displays of pertinent musical practice' (Hood 1971: 96). The notation developed in this research transcribes strategies from music, through ethnomusicology, to the auditory landscape.

For landscape sounds, we can sensibly defer to extensions from Western Art music for three of the parameters of sound notated in music. Words can also describe the timbre of landscape sounds; an extended palette of $p$ and $f$ markings can denote their volume; and pitch is not dominant in the sounds of landscape as pitch juxtapositions are largely unrelated and, even, where identifiable, are individual and short in duration. The greatest challenge lies, rather, in the notation of time, as sounds in landscape lack an identifiable durational reference, a tempo. For this investigation an alternative notion for the transcription of aperiodic time was considered. Musicologists Dieter Christensen and Bruno Nettl, in response to the difficulties of measuring tempo by metronome where metric stability is absent, proposed the notion of Inner Tempo. This they calculated as the 'average degree of rhythmic movement - to its total duration' (Christensen and Nettl 1960: 10). This amended ethnomusicology formed the method to transcribe the six hundred and fifty-five seconds of Australian landscape sounds in this study (figure $\mathbf{3}$ ).

\section{Above}

The final notation uses sounds previously recorded at Girraween ${ }^{2}$ to compose an auditory landscape. In order to locate these studies in the time and space of the earlier work, I drew them on tracing paper overlaid on the preceding studies. This approach conflated music notation, landscape sounds, and compositional intent. Like Green Meadows, the temporal approach to this composition is one of duration rather than time. There is not a definable pulse or trace of metronomic regularity, but rather a sequence of elements of different durations with varying qualities of time within them.

My composition of landscape sounds consists of five sections, using a combination of notational strategies from different sounds occurring together, to motive sounds to reveal spatial extent (figure 4). Rather than a rolling melodic contour, here, analogous to the land in which the sounds were recorded, the overall auditory range is flat, expansive, and monotonous. Where in Green Meadows there was a tension between the simultaneous occurrence of two speeds in the right and the left hands, here the tension is expressed through stereo separation of the sounds. This creates an enhanced sense of space in two ways: firstly, by spreading the components over a wider horizontal range through the separation into two channels; and secondly, by increasing the sense of spatial depth through adjusting volume, which is strongly perceived as distance. The dashed vertical lines at the beginning and end of the score denote structural divisions, rather than temporal ones. I consider this composed work not as finite, but rather as an auditory landscape, which will continue to resonate in listeners' imaginations, and grow.

\section{Conclusion}

I filmed the charcoal drawings in each of these studies to form new notations. Like a designed landscape, they contain both construction and demolition. As information accumulates, erasure creates space to accommodate subsequent transcriptions. This process causes constant choices about which material is retained, and which is discarded. It creates a constant shimmer between drawing and reflection. The vestigial marks bear witness to the activities that previously created them, and traces of past actions are visible in the surface. Like a landscape, these notations reveal not just lines of current activity, but past places visited. 


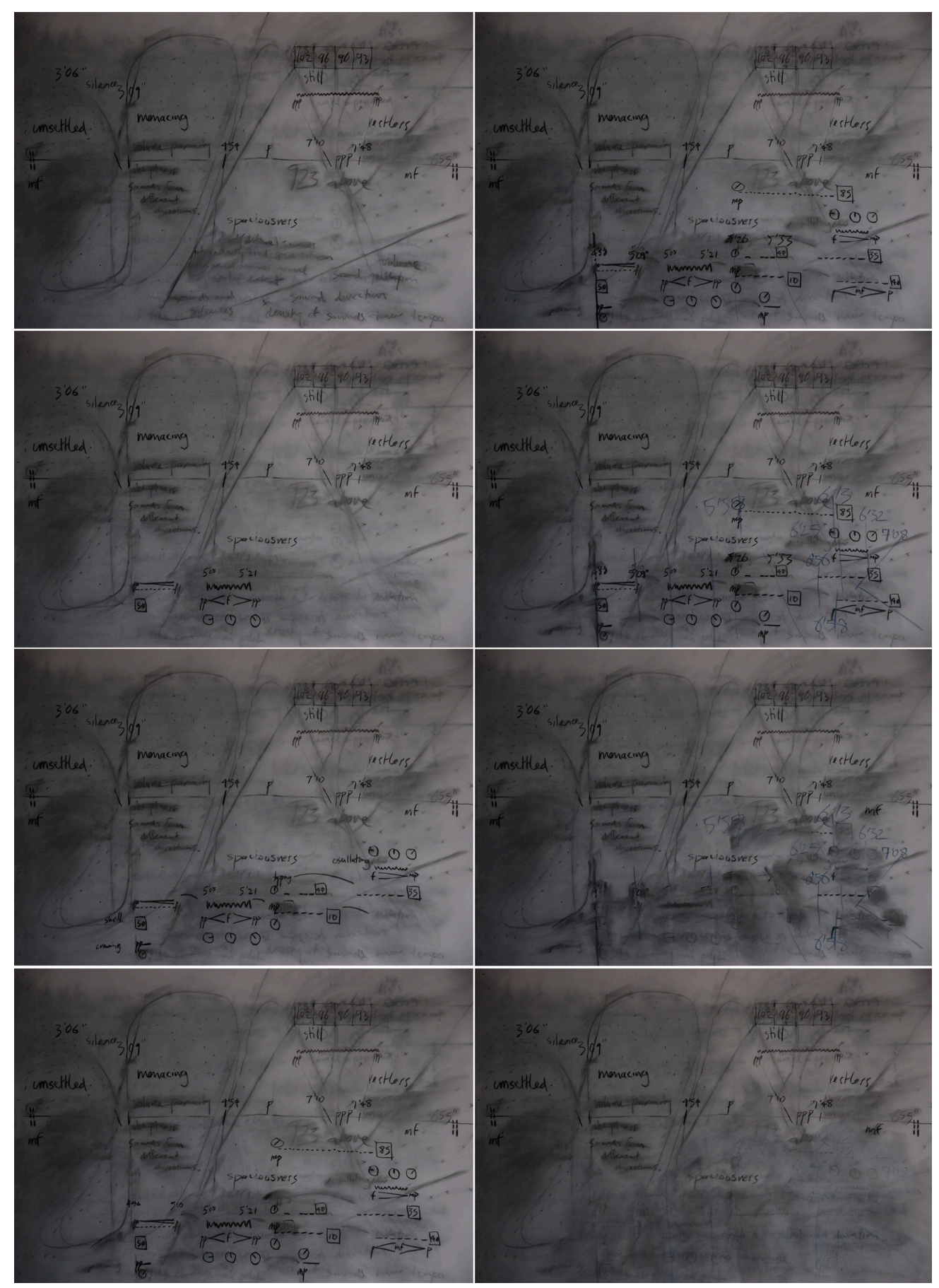

Figure 4: Extracts from the film of a prescriptive notation for an auditory landscape, titled 923 Above. David Buck, charcoal on paper, $1126 \mathrm{mmx} 1600 \mathrm{~mm}, 2013$. To be read vertically from upper left. To view the video, see DOI: http://dx.doi.org/10.5334/opt.cb.2. David Buck, video duration 2'07", 2013. 
Musicologist Paul Griffiths notes that 'music, in reaching from the mental to the physical world, must pass through a process of visualisation, alienating itself from pure sound' (Griffiths 1986: 5). Yet, through the inclusion of sound in these notations, rather than being decoded from solely the visual field, they can also be experienced aurally. In these films, rather than being distanced by the filter of notation, we are in fact immersed, complicit in its experience. This joining of landscape and notation has a seldom noted etymological connection: both landscape and notation are pictorial ways of representing or symbolising aspects of our surroundings. From its history in art, landscape may be more easily connected to its literal representation in pictures, but music notation is also a picture, a visual representation produced on a surface. The symbolic representation of sound in music notation in this study functions very closely to that of visual representations of landscape in the eighteenth century. At that time, representations of landscape provided an alternative canon to substitute for the inadequacies of a short designed landscape history. Music similarly functions in the design of an auditory landscape. By referencing music in the development of landscape design tools for sound, we benefit from the history of drawn records contained in Western music notation that date back to 830 A.D., to the Cantorium of St. Gall.

Besides Gilpin, other eighteenth century writers on landscape have also noted that a study of sound need not preclude vision. They believed that in providing sensory information for our perception of landscape, senses threw a reciprocal light on each other. Uvedale Price, in his Essays on the Picturesque (1810), noted that although the picturesque in name and reference implied the dominance of vision, other senses, including sound, were equally able to create the sensations of picturesque, beauty, or the sublime. Furthermore, the sounds he referred to were not just those passively found in nature, but those that could be composed. He noted that the music of Joseph Haydn for example, with its sudden abrupt transitions, was equally as applicable in the evocation of landscape as aspects from scenery.

The British composer Cornelius Cardew rather famously stated that 'notation and composition determine each other' (Cardew 1961: 21). If so, is landscape being created through these notations? John Ruskin, writing in Modern Painters, said of Turner: 'First he receives a true impression from the place itself ... and then he sets himself as far as possible to reproduce that impression in the mind of the spectator' (Ruskin 1904: 21-22). The films Six Hundred and Fifty Five Seconds and 923 above also seek to convey the experience within the Australian landscape, the absence of a visual focus, the almost imperceptible motion, and the dominance of sound. Like the work of Turner, these notations recreate in the mind of the observer a true impression of a place. If landscapes can be formed through evoking the same experience of a place through another media, then notation, as much as representation, can also create one.

Perhaps the reason for the curious absence of sound since Gilpin's and Price's compelling writings can be found in the paucity of drawing tools. While the representation of landscape in art has had tools to describe its visual nature, the corresponding tools for the representation of sound have been missing from design theory. This research then reconnects to the eighteenth century understanding of sound as a critical component of landscape through providing a notational language and method that allows for sounds to be drawn.

Notations by others in the twentieth century, including Lawrence Halprin, Kevin Lynch, Galia Hanoch-Roe, Philip Thiel, and Bernard Tschumi, brought aspects of music notation into design notations, but curiously left sound behind. These studies are a first contemporary attempt to bring musical notation into landscape design through its ability to help us notate sound itself. This research connects us to the beginnings of designed landscape in England in 
the early seventeenth century. The founder of The Spectator, Joseph Addison, writing in the summer of 1712, understood landscape as both a mental construct and as a physical realm. These two separate worlds in fact informed each other, as the imagination could be as potent as actually having them in one's view. What we perceive informs the way we understand the world around us. By adding sound to the design of landscapes, we make the auditory experience more prominent in our subsequent perception of places.

The commonly noted OED definition of landscape, from 1725, reaffirmed recently by John Wiley as 'a unit of visual space' (Wiley 2007: 91), was preceded by an earlier reference to landscape in 1603. This defined landscape as a picture, a representation of natural inland scenery. If the beginning of landscape in Western culture was not a physical place but a drawing, then my research, which is a study through drawing, has in fact also created a landscape.

\section{Notes}

${ }^{1}$ Including Bernard Tschumi's Manhattan Transcripts (1981), Lawrence Halprin's "Motation" (1965), and Lynch, Appleyard and Myer's notations in The View from the Road (1965).

${ }^{2}$ Girraween National Park is located in southern Queensland, about 300 kilometres from Brisbane, in the area behind the fertile coastal belt known as the hinterland. Its landscape is a mix of granite outcrops, Eucalyptus forest, and wild flower grasslands.

\section{References}

Brougham, H, Fox, C and Pace, I (eds.) 1997 Uncommon Ground The Music of Michael Finnissy. Aldershot: Ashgate Publishing Limited.

Busoni, F 1965 The Essence of Music and Other Papers. New York: Dover Publications.

Cardew, C 1961 Notation-Interpretation, Etc. Tempo, 58: pp. 21-33. DOI: http://dx.doi. org/10.1017/S0040298200045873

Christiansen, D and Nettl, B 1960 Inner Tempo and Melodic Tempo. Ethnomusicology, 4 (1): pp. 9-14. DOI: http://dx.doi. org/10.2307/924229

Gilpin, W 1808 Observations, on Several Parts of England, Particularly the Mountains and Lakes of Cumberland and Westmorland, Relative Chiefly to Picturesque Beauty, Made in the Year 1772. Vol 2. London: Cadell and Davis.

Goodman, N 1976 Languages of Art: An Approach to the Theory of Symbols. Indianpolis: Hackett Publishing Company.

Griffiths, P 1986 Sound-Code-Image. In: Arts Council (ed.) Ethnomusicology An Introduction. London: Arts Council of Great Britain.

Hood, M 1971 The Ethnomusicologist. Los Angeles: McGraw-Hill Book Company.

Price, U 1810 Essays on the Picturesque, as Compared with the Sublime and Beautiful, and on the Use of Studying Pictures, for the Purpose of Improving Real Landscape. London: J. Mawman.

Ruskin, J 1904 Modern Painters. Vol. 4. London: George Allen.

Wiley, J 2007 Landscape. Routledge: London.

\footnotetext{
How to cite this article: Buck, D N 2014 Drawing Sound as Landscape. Opticon1826, (16): 16, pp. 1-8, DOl: http://dx.doi.org/10.5334/opt.cb

Published: 15 October 2014

Copyright: (c) 2014 The Author(s). This is an open-access article distributed under the terms of the Creative Commons Attribution 3.0 Unported License (CC-BY 3.0), which permits unrestricted use, distribution, and reproduction in any medium, provided the original author and source are credited. See http://creativecommons.org/licenses/by/3.0/.
} 